\title{
Detection of lymphocytes in malignant gliomas by monoclonal antibodies
}

\author{
KENJIRO YASUDA, ${ }^{*}$ THOMAS ALDERSON, JACK PHILLIPS, $\dagger$ KAROL SIKORA \\ From the Ludwig Institute for Cancer Research, MRC Centre, Hills Road, Cambridge; and the Department of \\ Neurosurgery, St Laurence's Hospital, $†$ Dublin
}

SUMMARY Lymphocytes are not present in normal brain but are known to infilitrate malignant gliomas. The reasons for this infiltration and the signals involved are not understood. The lymphocyte content of 15 malignant gliomas removed at time of surgery was studied, using monoclonal antibodies to $\mathrm{T}$ and $\mathrm{B}$ cell surface antigens and immunofluorescence. An average of $41 \%$ of infiltrating cells possessed surface Ig, with $21 \%$ bearing the common $\mathrm{T}$ cell marker. There was no evidence of oligoclonal restriction of light chain types.

There is good evidence that human solid tumours contain lymphocytes and macrophages. ${ }^{12}$ The function of these lymphoreticular cells, and in particular their anti-tumour role, is still poorly defined. ${ }^{3}$ The brain lacks a conventional lymphatic system and has for many years been regarded as an immunologically privileged site. ${ }^{4}$ Perivascular lymphocytic cuffs have been described in histological sections of human gliomas $^{5-7}$ and macrophages have been isolated from brain tumours. ${ }^{8} \mathrm{~A}$ recent study has demonstrated the presence of lymphocytes in malignant glioma by the use of rosetting assays in mechanically or collagenase disaggregated suspension cells. ${ }^{9}$ We have been using such lymphocytes to produce human monoclonal antibodies and test the reactivity of such antibodies against glioma tissue. ${ }^{10} 11$ The nature of the lymphocytes associated with gliomas is not well defined. There are as yet no studies defining the types of lymphocyte involved and the histological relationship of these cells to tumour. In this study we have used a set of commercially available monoclonal antibodies to define the population of lymphocytes in gliomas. We have used immunofluorescence and immunoperoxidase techniques to examine both cryostat *Present address: Department of Anatomy, Keio University,
Shinjuki, Tokyo 160, Japan.

Address for reprint requests: Dr Karol Sikora, The Ludwig Institute for Cancer Research, MRC Centre, Hills Road, Cambridge CB2 2QH, UK.

Received 29 December 1982 and in revised form 26 March 1983. Accepted 16 April 1983 sections and thick smear preparations to assess the optimal methodology for lymphocyte definition. Biopsy material from 15 patients with grade III-IV malignant glioma was then examined and the population of infiltrating $\mathrm{T}$ and $\mathrm{B}$ lymphocytes quantified.

\section{Materials and methods}

Glioma tissue was obtained from patients at the time of initial surgery for suspected malignant glioma. All patients studied were found to have grade III-IV malignant glioma. Approximately $1 \mathrm{~g}$ of tissue was kept in cold Dulbecco's modified eagle medium (DMEM) and processed within one hour of surgery. Tissue was frozen and stored in liquid nitrogen until required. Cryostát sections 5-7 $\mu \mathrm{m}$ in thickness were prepared from frozen tissue and applied to a clean dry microscope slide without any fixation. Tissue was teased in DMEM with fine forceps, fragments taken up in a capillary tube and placed on a glass slide and spread by the edge of a second microscope slide in a matter analogous to the preparation of blood films. Sections or smears were dried quickly using a fan and stored at $-20^{\circ} \mathrm{C}$ until required.

\section{Antisera}

Monoclonal anti-human Lyt3 antibody (NE1-016) was purchased from New England Nuclear (Boston, Massachusetts). This mouse monoclonal antibody is a mouse IgG $2 b$ which recognises the Lyt 3 antigen present on the cell surface of all human $\mathrm{T}$ lymphocytes. ${ }^{12}$ It was produced by immunisation of mice with peripheral blood lymphocytes. Monoclonal mouse anti-human Ia was also obtained from New England Nuclear (NE1-011) which reacts with only B cells which bear the Ia antigen. ${ }^{13}$ Monoclonal mouse antihuman light chain kappa and light chain lambda antibodies $^{14}$ were obtained from Bethesda Research Laboratories, Gaithersburg, Maryland. These antibodies were 
prepared by immunising Balb/c mice with three injections of either kappa or lambda Bence Jones proteins. Splenic lymphocytes were then fused with mouse myeloma line and supernatants of hybridomas assayed by an Elisa assay on free kappa or lambda Bence Jones proteins. These antibodies have been previously shown to be totally specific to the light chain type. Rabbit anti-mouse IgG FITC conjugate was a product of Miles-Yeda Limited, Rehovot, Israel, and was prepared by immunising a rabbit with mouse serum. Rabbit anti-mouse peroxidase conjugate was purchased from Sigma Chemical Company (St Louis, Missouri) and recognised whole mouse immunoglobulin. Monoclonal antibodies were diluted $1 / 1000$ in $0.05 \mathrm{M}$ phosphate buffered saline $\mathrm{pH} 7 \cdot 2$ containing $0 \cdot 85 \% \mathrm{NaCl}$ (PBS). The FITC conjugated antiserum was diluted at $1 / 256$ with PBS and the peroxidase conjugated serum diluted $1 / 1000$ with PBS.

\section{Indirect immunofluorescence}

After fixation in $10 \%$ formalin for 10 minutes, the slides were washed twice in PBS for 10 minutes, incubated with $2 \%$ bovine serum albumen (BSA) for 10 minutes and incubated with monoclonal antibody for 30 minutes at room temperature. After further washing and treating with $2 \%$ BSA the slides were incubated with the anti-mouse antibody conjugated with FITC for 30 minutes at room temperature. After washing the slides were mounted in buffered glycerine (glycerine, 9 parts; $1 \mathrm{M}$ Tris $\mathrm{HCl}$ buffer pH 8.4, 1 part).

\section{Indirect immunoperoxidase}

Formalin fixed slides were washed and treated with $0.1 \%$ trypsin and $0.1 \% \mathrm{CaCl}_{2}$ for 10 minutes at room temperature. ${ }^{15}$ After washing in PBS the slides were treated with $0.3 \%$ hydrogen peroxide dissolved in absolute methanol for 20 minutes and washed in PBS. Two per cent BSA was used to block nonspecufic binding. Monoclonal antibody was added for 30 minutes at room temperature. After washing in PBS and further incubation in 2\% BSA antimouse IgG peroxidase conjugate $(1 / 1000)$ was added for 30 minutes at room temperature in the dark. After washing in PBS the slides were stained with freshly prepared diamino benzidine solution (DAB) containing 0.02\% DAB, 0.005\% $\mathrm{H}_{2} \mathrm{O}_{2}$ in $0.05 \mathrm{M}$ Tris $\mathrm{HCl}$ buffer $\mathrm{pH} 7.4$ for 15 minutes. After washing with distilled water and staining with $2 \%$ aqueous methyl green for seven minutes the slides were dried, dehydrated in $80 \%, 95 \%$ and absolute alcohol, cleared in xylene and mounted in DPX.

Control specimens were treated as described in the staining procedure except that the monoclonal antibodies were omitted or replaced by $2 \%$ bovine serum albumin. All sections and smears were examined by a Zeiss fluorescence microscope and photographed by using Kodak Ektachrome 400. At least 100 small lymphocytes were counted and the proportion staining with different monoclonal antibodies assessed as a percentage.

\section{Results}

Immunoperoxidase and immunofluorescence was carried out on both sections and smears using
Table 1

\begin{tabular}{|c|c|c|c|c|}
\hline & \multicolumn{2}{|c|}{ Section } & \multicolumn{2}{|c|}{ Smear } \\
\hline & $I F$ & $I P X$ & IF & $I P X$ \\
\hline $\begin{array}{c}\text { Patient I } \\
\alpha \text { Lyt } 3 \\
\alpha \text { Ia } \\
\alpha \kappa \\
\alpha \hat{\lambda} \\
\end{array}$ & $\begin{array}{l}0 \\
0 \\
4 \\
8\end{array}$ & $\begin{array}{r}5 \\
19 \\
5 \\
8 \\
\end{array}$ & $\begin{array}{l}29 \\
35 \\
19 \\
12\end{array}$ & $\begin{array}{l}17 \\
26 \\
15 \\
11\end{array}$ \\
\hline $\begin{array}{c}\text { Patient } 2 \\
\alpha \text { Lyt } 3 \\
\alpha I a \\
\alpha \kappa \\
\alpha \lambda \\
\end{array}$ & $\begin{array}{r}2 \\
0 \\
10 \\
7 \\
\end{array}$ & $\begin{array}{r}8 \\
12 \\
5 \\
9 \\
\end{array}$ & $\begin{array}{l}17 \\
49 \\
27 \\
19 \\
\end{array}$ & $\begin{array}{l}11 \\
37 \\
22 \\
13 \\
\end{array}$ \\
\hline $\begin{array}{c}\text { Patient } 3 \\
\alpha \text { Lyt } 3 \\
\alpha \text { Ia } \\
\alpha \kappa \\
\alpha \lambda\end{array}$ & $\begin{array}{l}3 \\
7 \\
2 \\
8\end{array}$ & $\begin{array}{l}0 \\
0 \\
2 \\
1\end{array}$ & $\begin{array}{l}21 \\
63 \\
47 \\
12\end{array}$ & $\begin{array}{l}15 \\
19 \\
13 \\
13\end{array}$ \\
\hline
\end{tabular}

material from the patients. The greatest yield of positively staining cells was obtained using immunofluorescence on thick smears (table 1). Cryostat sections gave poor staining patterns and the results were often difficult to interpret. These differences presumably reflect the surface expression of the antigens detected by the antibodies and the greater preservation of the cell surface in smear preparations when compared to cryostat sections. Immunofluorescence gave clearer definition and less artefact in staining than immunoperoxidase. Examples of cells stained by the four monoclonal antibodies used are shown in fig 1a-d.

The distribution of lymphocyte subtypes in 15 biopsies from patients with malignant glioma is shown in table 2. Four patients showed no evidence of lymphocyte infiltration. The remaining 11 show differing amounts of infiltration within the tumour. The distribution of lymphocyte subtypes is remarkably similar in all these patients with a preponderance of B lymphocytes (Ia bearing with sIg expression) compared with $\mathrm{T}$ cells. Three samples of normal brain were analysed in a similar manner and have shown no evidence of lymphocytic infiltration. Mean $T$ cell content within the lymphocyte was $21 \%$ and B cell (Ia bearing) $41 \% . \kappa / \lambda$ ratios varied from 0.7 to 3.9 with a mean of $1 \cdot 8$. No evidence of oligoclonal restriction of light chain types was observed. ${ }^{14}$

\section{Discussion}

The predominant type of lymphocyte which infiltrate glioma tissue have been found to be B lymphocytes. The localisation of such cells within the glioma suggests a possible role in producing antibody directed against antigens expressed on the rapidly growing malignant cells. The use of thick smears of glioma tissues rather than frozen sections has clearly per- 

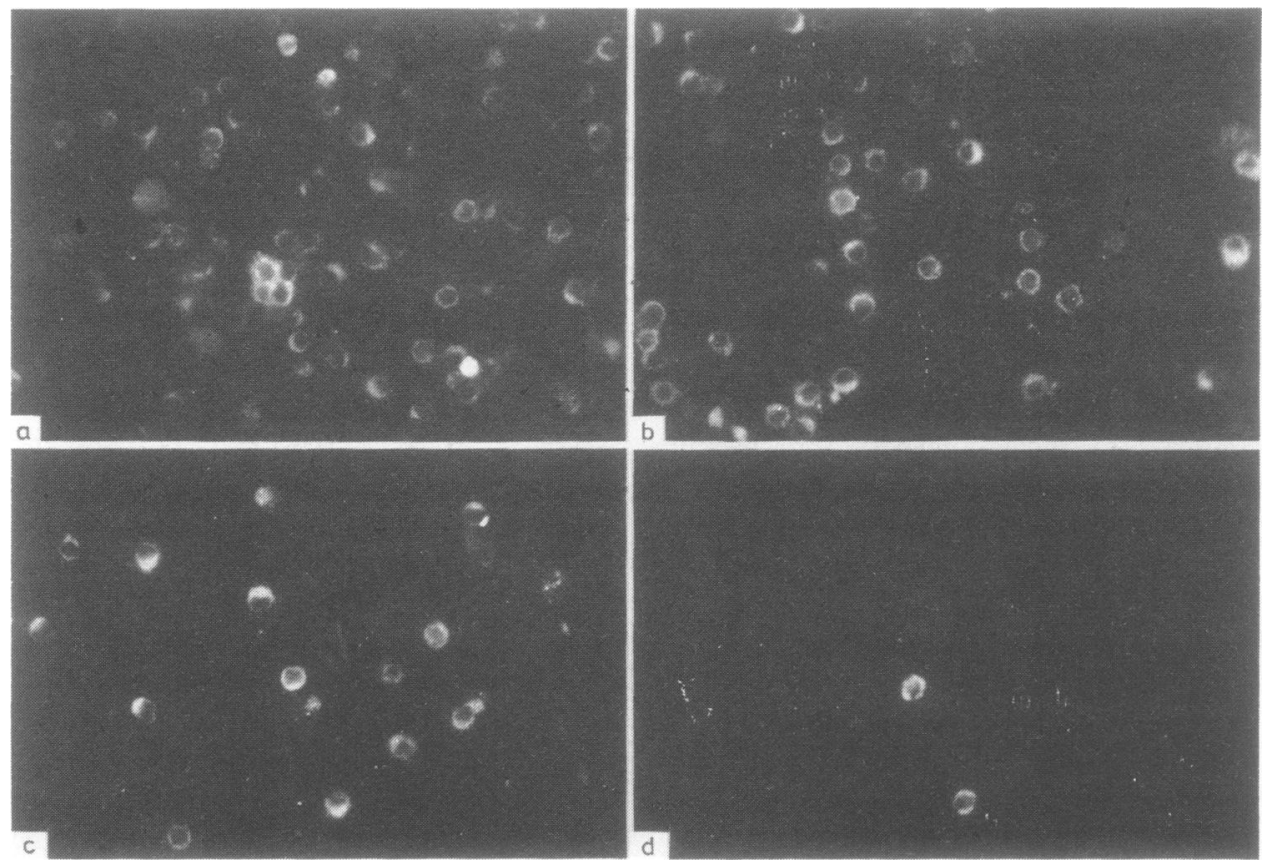

Fig Immunofluorescence of thick smears of malignant glioma stained with (a) $\alpha$ human Ia antibody, (b) $\alpha$ human light chain $\kappa$ antibody, (c) $\alpha$ human light chain $\lambda$ antibody, $(d), \alpha$ human Lyt 3 (anti $T$ cell) antibody

mitted the demonstration of numerous lymphocytes which could not be detected easily on cryostat sections. The present study reveals the presence of lymphocytes in the majority of malignant gliomas. Although the lymphocytes make up less than $20 \%$ of the total cells within the smears, there are clearly areas of intense lymphocytic infiltration. This confirms observations using rossetting techniques ${ }^{9}$ or conventional polyclonal antisera. ${ }^{16}$ The triggering factors for this infiltration are unclear. We were unable to demonstrate lymphocytes in normal brain from three patients in whom post mortem material was obtained. The demonstration of a lymphocyte infiltration in these tumours led to the use of such cells in hybridoma fusion systems Individual B lymphocytes from within tumours can now be immortalised to produce human monoclonal antibodies. In this way the nature of the determinants

Table 2

\begin{tabular}{|c|c|c|c|c|c|c|c|c|}
\hline & No & Age (yr) & Sex & $\begin{array}{l}\text { Histological } \\
\text { infiltrate }\end{array}$ & $\alpha L y t 3$ & $\alpha I a$ & $\alpha \kappa$ & $\alpha \lambda$ \\
\hline Malignant gliomas & $\begin{array}{r}1 \\
2 \\
3 \\
4 \\
5 \\
6 \\
7 \\
8 \\
9 \\
10 \\
11 \\
12 \\
13 \\
14 \\
15\end{array}$ & $\begin{array}{l}21 \\
60 \\
32 \\
15 \\
32 \\
41 \\
39 \\
65 \\
32 \\
13 \\
46 \\
60 \\
46 \\
69 \\
57\end{array}$ & $\begin{array}{l}\mathbf{F} \\
\mathbf{M} \\
\mathbf{F} \\
\mathbf{F} \\
\mathbf{M} \\
\mathbf{F} \\
\mathbf{F} \\
\mathbf{M} \\
\mathbf{M} \\
\mathbf{F} \\
\mathbf{M} \\
\mathbf{F} \\
\mathbf{F} \\
\mathbf{F} \\
\mathbf{M}\end{array}$ & $\begin{array}{l}++ \\
+++ \\
++ \\
++ \\
++ \\
+ \\
+ \\
++ \\
++ \\
++ \\
+ \\
+ \\
++\end{array}$ & $\begin{array}{r}29 \\
17 \\
21 \\
17 \\
26 \\
0 \\
14 \\
22 \\
0 \\
15 \\
17 \\
25 \\
0 \\
0 \\
29\end{array}$ & $\begin{array}{r}35 \\
49 \\
63 \\
48 \\
42 \\
0 \\
28 \\
14 \\
0 \\
39 \\
57 \\
38 \\
0 \\
0 \\
39\end{array}$ & $\begin{array}{r}19 \\
27 \\
47 \\
31 \\
12 \\
0 \\
21 \\
13 \\
0 \\
28 \\
41 \\
32 \\
0 \\
0 \\
17\end{array}$ & $\begin{array}{r}12 \\
19 \\
12 \\
19 \\
14 \\
0 \\
18 \\
19 \\
0 \\
14 \\
13 \\
13 \\
0 \\
0 \\
0 \\
21\end{array}$ \\
\hline
\end{tabular}


seen by this infiltrating population can be investigated. Techniques are now also available by which intratumoural $\mathrm{T}$ cells can be immortalised either by growth in interleukin 2 or by the production of $T$ cell hybridomas. ${ }^{17}$ Thus the role of the infiltrating lymphocyte in patients with cancer can be determined.

Kenjiro Yasuda thanks Downing college, Cambridge for a visiting fellowship.

\section{References}

1 Underwood JCE. Lymphoreticular infiltration in human tumours. Br J Cancer 1974;30:538-48.

2 James K, McBride B, Stuart A. The macrophage and cancer. Proc Eures Symp. Edinburgh, 1977.

3 Vose BM, Moore M. Suppressor cell activity of lymphocytes infiltrating human lung and breast tumours. Int $J$ Cancer 1979;24:574.

4 Scheinberg LC, Edelman FL, Levy WA. Is the brain an immunologically privileged site? Arch Neurol 1964; 248:248-57.

5 Ridley A, Cavanagh JB. Lymphocyte infiltration in gliomas: evidence of possible host resistance. Brain 1976;94:117-24.

- Takeuchi J, Barnard RO. Perivascular lymphocytic cuffing in astrocytomas. Acta Neuropathol 1976;35: 265-71.

7 Palma L, Dilorenzo N, Guidetti B. Lymphocytic infiltra- tion in primary glioblastomas and reciduous gliomas. $J$ Neurosurg 1978;49:854-62.

8 Wood G, Morantz RA. Immunohistologic evaluation of the lymphoreticular infiltrate of human central nervous system tumours. J Natl Cancer Inst 1979;62:485-91.

9 Phillips JP, Eremin O, Anderson JR. Lymphoreticular cells in human brain tumours and in normal brain. $\mathrm{Br} \mathrm{J}$ Cancer 1982;45:61-9.

10 Sikora K, Alderson T, Phillips J, Watson JV. Human hybridomas from malignant gliomas. Lancet 1982; 1:11-4.

"Sikora K, Alderson T, Ellis J, Phillips J, Watson J. Human hybridomas from patients with malignant disease. Br J Cancer 1983;47:135-45.

12 Kamoun M, Martin PJ, Hansen J, Brown MA, Siadak AW, Nowinski RC. Identification of a human $T$ lymphocyte surface protein associated with the $E$ rosette receptor. J Exp Med 1981;153:207-12.

13 Hansen JA, Martin P, Nowinski RC. Monoclonal antibodies identifying a novel $\mathrm{T}$ cell antigen and Ia antigens of human lymphocyte. Immunogenetics (in press).

14 Kennett RH. In: Kennett RH, McKearn TJ, Bechtol, KB eds. Monoclonal Antibodies. New York: Plenum Press, 1980.

15 Hautzer VW, Wittkuhn JF, McCaughey WTE. Trypsin digestion in immunoperoxidase staining. $J$ Histochem Cytochem 1980;28:52-3.

16 Stavrou D, Anzil AP, Weidenbach W, Root H. Immunofluorescence study of lymphocytic infiltration in gliomas. J Neurol Sci 1977;33:275-82.

17 Moller G. T cell clones. Immunol Rev 1981;54:1-27. 